\title{
Trypanosoma cruzi: Clonal Structure of Parasite Strains and the Importance of Principal Clones
}

\author{
Sonia G Andrade \\ Laboratório de Doença de Chagas Experimental, Centro de Pesquisas Gonçalo Moniz-Fiocruz, \\ Rua Valdemar Falcão 121, 40295-001 Salvador BA, Brasil
}

Key words: Trypanosoma cruzi - clones - strains - biodemes

Trypanosoma cruzi strains, are complex multiclonal populations that differ in their genetic and biological characteristics and in their behavior in the vertebrate host. T. cruzi strains represent subspecies, based on intrinsic characters as antigenic composition (Andrade et al. 1981) susceptibility to chemotherapy (Andrade et al. 1975, Brener et al. 1976), isoenzyme patterns ( Miles et al. 1980, Andrade et al. 1983, Tibayrenc \& Ayala 1988) and genomic profils of kDNA (Morel et al. 1980, Avila et al. 1990). Studies on the host-parasite relationships have disclosed marked differences in the determinism of tissue lesions, dependent on tropism, virulence and pathogenicity of $T$. cruzi strains (Andrade et al. 1970, 1985). An extensive study on the biological characteristics of the natural strains and histopathological profile in experimental animals, led to grouping them since 1970 (Andrade et al.), into a few well defined types or biodemes: Types I, II and III (Andrade et al. 1970, 1985, 1997). This biological classification has been recommended by WHO (1986). A possible genetic basis for the biological behavior of the three strain types has been searched at a phenotypic level, by isoenzymic analysis of the prototypes, and other representative strains, isolated from different geographical areas (Andrade et al. 1983). The enzymes PGM (phosphoglucomutase), GPI (glucosephosphate isomerase), ALAT (alanine amino transferase), ASAT (aspartate aminotransferase), allowed a good discrimination between the three strain types and a clear correlation with biological data. By studying 15 gene loci coding for enzymes, in stocks of T. cruzi from different geographical areas, Tibayrenc and Ayala (1988), have suggested the possibility of a clonal structure for T. cruzi strains, based on the existence of clonal

Fax: +55-71-376.4252.

E-mail: sgandrade@cpgm.fiocruz.br

Received 9 June 1999

Accepted 9 August 1999 lines without sexual interactions, separated by a long evolutionary process. This suggested a possible correlation between biochemical classification and biological properties. According to those authors, T. cruzi strains are natural clones and the natural selection, favouring only certain genetic pattern or combinations, could account for a limited number of isoenzyme strains, represented by three major clones. By using several parameters in vitro, Revollo et al. (1998) has confirmed the hypothesis of a correlation between biological and phylogenetic variability of $T$. cruzi, by multilocus enzyme electrophoresis (MLEE), and random amplification of polymorphic DNA (RAPD), based on the genetic distances. Biological types (biodemes), are correlated with the zymodemes which were described by Miles et al. (1980), with the exception of the Type I strain that presented a peculiar electrophoretic profil not described previously (Andrade et al. 1983) and that has been subsequently identified as Z2b; biodeme Type II corresponds to Z2, and Type III, to Z1.

In a survey of 138 strains isolated from different hosts, in different geographical areas of Brazil and other countries of Central and South America, the ubiquitary distribution of the three biodemes was evident (Andrade \& Magalhães 1997). However, the exclusive presence of Type II, Z2 strains in the endemic areas of São Felipe and Mambaí was patent, and the predominance of Type I, Z2b in several South America countries became evident, as well as the correlation of Type III, ZI strains with a sylvatic origin. The stability of the biological and isoenzymic characteristics of strains isolated from the endemic area of São Felipe, BA, all of them included into the Type II, Z2, points to the presence of "principal clones" in this area (Andrade 1974, Andrade et al. 1983).

An investigation was performed to stablish the characteristics of the clonal populations of the 21 SF strain, one of the prototypes of the several strains from São Felipe, which was isolated from a patient during the acute phase of the disease. It has been maintained in laboratory by successive passages in mice for more than 15 years. Cloning has 
been performed by isolating one single parasite from peripheral mouse blood and injecting it intraperitoneally into one suckling mouse. From each positive animal, thus representing one clone, inoculum was individually obtained and injected into suckling mice. Five clones and 14 subclones have been obtained and submitted to biological, biochemical and genetic characterization (Campos \& Andrade 1996, Campos et al. 1999). Biological and biochemical characterization have shown that all the clones and subclones revealed parasitemic profils characteristics for Type II strains, and similar to the parental strain (21SF), in the infected mice (Campos \& Andrade 1996). The biochemical analysis for the enzymes ALAT, ASAT, PGM and GPI, have shown the electrophoretic Z2 patterns, similar to the parental strain. Biological and isozymic homogeneity of the 5 clones and 14 subclones of the $21 \mathrm{SF}$ strain seems to indicate that this $T$. cruzi strain is composed predominantly by similar populations considering their phenotypic characteristics. However, as registered by McDaniel and Dvorak (1993), clones with the same isoenzymic profils, can differ in their schizodemes. Considering the stability of the 21 SF strain and the homogeneity of the biological and isoenzymic characters of its clones and subclones, the genetic profil of this clonal population was then investigated. A comparative analysis by polymerase chain reaction (PCR) amplified minicircles of kinetoplast DNA, of the several clones and subclones, was performed with the objective of clarifying their genomic profil (Campos et al. 1999). Schizodeme was established by comparative study of the fragments obtained from digestion of the $330 \mathrm{bp}$ fragments amplified by PCR, from the variable regions of the minicircles and digested by restriction endonucleases Rsa I and Hinf I. The results have shown a high percentual of similarity between the restriction fragment lenght polymorphism (RFLP) for the parental strain and its clones and among these individual clones and their subclones, at a level of 80 to $100 \%$. This homology indicates the predominance of the same "principal clone" in the $21 \mathrm{SF}$ strain. These results suggest the possibility that $T$. cruzi strains with similar biological and isoenzymic patterns, circulating in the endemic area of São Felipe, are representative of one dominant clone. Well adapted clones can predominate and be selected by environmental conditions and circulate in different areas (Tibayrenc \& Ayala 1988). The presence of a dominant clone in the strains isolated from one endemic area, revealed by biological, biochemical and genetic parameters, could be responsible for a predominant tropism of the parasites. This, certainly, may contribute to the pattern of clinico-pathological manifestations, in one geo- graphical area. Macedo and Pena (1998) suggests that multiclonal strains are formed by clonally propagating organisms with different tissue tropisms, correlated with complementary molecular interactions between the invading clones of $T$. cruzi and the host tissues. The biological and biochemical characteristics of $T$. cruzi strains are correlated with different tissue lesions, as first observed in acute infection of mice with strains of different types (Andrade 1985). During the chronic phase, a clearcut influence of the biological type of strain on the histopathological lesions has also been detected. The Type III strains (Z1) were the most pathogenic, determining intense cardiac and skeletal muscle lesions, with patent tissue parasitism, even at the late stage of infection. During the chronic phase, cardiac lesions also occurred in the mice infected with Types I and II strains (Andrade 1990). Besides cardiac lesions, these two types of strain determined significant involvement of the neuronal cells of the myoenteric plexus. Although segmentar inflammatory alterations, in the ganglionic cells, has been detected with the three types of strains, they are more destructive for the neuronal cells, in Y strain (Type I) infections (Souza et al. 1996). The Zymodeme 2 has been identified by Lauria-Pires and Teixeira (1996) in one T. cruzi stock from a patient with the digestive form of Chagas disease, and several clones, suggesting the participation of this zymodeme, corresponding to Type II strain, in the pathogenesis of megasyndromes in Chagas disease. Histopathological evidences that cardiac lesions occurred with the three types of strains, correlates well with the fact that a chronic cardiopathy is the main manifestion of human Chagas disease, anywhere this parasitic disease is endemic.

Correlations between the sensibility to benznidazole and nifurtimox and the genetic distances of $T$. cruzi stocks, have been described by Revollo et al. (1998). This is in agreement with the observation that resistance to chemotherapy is related to the biological characteristics of the $T$. cruzi strains (Andrade et al. 1985) . The prototype of Type III strain, the Colombian strain, which is highly resistant to chemotherapy, has recently been cloned, showing an uniformity of biological and isoenzymic characters of its clones. Also it has maintained resistance to chemotherapy, thus confirming the hypothesis that a stable strain represents a predominant clonal population. In the endemic area of Montalvânia, MG, were an overlap between the sylvatic and domestic populations of triatominae has occurred (Luquetti et al. 1986), Types II and III strains have been identified (Andrade et al. 1992); clinical results of treatment with benznidazole and nifurtimox and the response 
to treatment in mice infected with these strains, that have been isolated from the same patients of this area, revealed $82 \%$ of coincidence (Andrade et al. 1992).

The identification of different biological types, and the genetic confirmation of the existence of populations with significant genetic distances, leads to the conclusion that "principal clones", circulating in one endemic area can be responsible for the disease manifestations and the type of chemotherapic responses seen in patients of these areas.

\section{REFERENCES}

Andrade SG 1974. Caracterização de cepas do Trypanosoma cruzi isoladas no Recôncavo Bahiano. Rev Pat Trop 3: 65-121.

Andrade SG 1985. Morphological and behavioral characterization of Trypanosoma cruzi strains. Rev Soc Bras Med Trop 18: (Suppl.): 39-46.

Andrade SG 1990. Influence of Trypanosoma cruzi strain on the pathogenesis of chronic myocardiopathy in mice. Mem Inst Oswaldo Cruz 85: 17-25.

Andrade SG, Magalhães JB 1997. Biodemes and zymodemes of Trypanosoma cruzi strains: correlations with clinical data and experimental pathology. Rev Soc Bras Med Trop 30: 27-35.

Andrade SG, Andrade V, Rocha Filho FD, Barral Netto M 1981. Análise antigênica de diferentes cepas do Trypanosoma cruzi. Rev Inst Med Trop São Paulo 23: 245-250.

Andrade SG, Carvalho ML, Figueira RM 1970. Caracterização morfobiológica e histopatológica de diferentes cepas do Trypanosoma cruzi. Gaz Méd Bahia 70: 32-42.

Andrade SG, Figueira RM, Carvalho ML, Gorini DF 1975. Influência da cepa do Trypanosoma cruzi na resposta à terapêutica experimental pelo Bay 2502. Rev Inst Med Trop São Paulo 17: 380-389.

Andrade SG, Magalhães JB, Pontes AL 1985. Evaluation of chemotherapy with benznidazole and nifurtimox in mice infected with Trypanosoma cruzi of different types. Bul WHO 63: 721-726.

Andrade SG, Rassi A, Magalhães JB, Ferrioli Filho F, Luquetti AO 1992. Specific chemotherapy of Chagas disease: a comparison between the response in patients and experimental animals inoculated with the same strain. Trans $R$ Soc Trop Med Hyg 86: 624626.

Andrade V, Brodskyn C, Andrade SG 1983. Correlation between isoenzyme patterns and biological behavior of different strains of Trypanosoma cruzi. Trans R Soc Trop Med Hyg 77: 796-799.

Avila H, Gonçalves AM, Nehme MS, Morel CM, Simpson 1990. Schizodeme analysis of Trypanosoma cruzi stocks from South and Central America by analysis of PCR-amplifiable minicircle variable region sequences. Mol Biochem Parasitol 42: 175-188.

Brener Z, Costa CAG, Chiari E 1976. Differences in the susceptibility of Trypanosoma cruzi strains to active chemotherapeutic agents. Rev Inst Med Trop São Paulo 18: 450-455.

Campos RMF, Andrade SG 1996. Characterization of subpopulations (clones and subclones) of the $21 \mathrm{SF}$ strain of Trypanosoma cruzi after longlasting maintenance in the laboratory. Mem Inst Oswaldo Cruz 91: 795-800.

Campos RF, Gonçalves MS, Reis EAG, Reis MG, Andrade SG 1999. Comparative analysis by polymerase chain reaction amplified minicircles of kinetoplast DNA of a stable strain of Trypanosoma cruzi from São Felipe, Bahia, its clones and subclones: possibility of predominance of a principal clone in this area. Mem Inst Oswaldo Cruz 94: 23-29.

Lauria-Pires L, Teixeira ARL 1996. Virulence and pathogenicity associated with diversity of Trypanosoma cruzi stocks and clones derived from Chagas disease patients. Amer J Trop Med Hyg 55: 304-310.

Luquetti AO, Miles MA, Rassi A, Rezende JM, Souza A, Povoa M, Rodrigues I 1986. Trypanosoma cruzi: zymodeme associated with acute and chronic Chagas disease in Central Brasil. Trans R Soc Trop Med Hyg 80: 462-470.

Macedo AM, Pena SDJ 1998. Genetic variability of Trypanosoma cruzi: implications for the pathogenesis of Chagas disease. Parasitol Today 14: 119123.

McDaniel JP, Dvorak JA 1993. Identification, isolation and characterization of naturally occurring Trypanosoma cruzi variants. Mol Biochem Parasitol 57: 213-222.

Miles MA, Lanham SM, Povoa M 1980. Further enzymic characters of Trypanosoma cruzi in their evaluation for strain identification. Trans $R$ Soc Trop Med Hyg 74: 221-237.

Morel C, Chiari E, Camargo EP, Mattei DM, Romanha AJ, Simpson L 1980. Strains and clones of Trypanosoma cruzi can be characterized by patterns of restrictions endonuclease products of kinetoplast DNA minicircles. Proc Natl Acad Sci 77: 6810-6814.

Revollo S, Oury B, Laurent J-P, Barnabé C, Quesney V, Carrière V, Noel S, Tibayrenc M 1998. Trypanosoma cruzi: impact of clonal evolution of the parasite on its biological and medical properties. Exp Parasitol 89: 30-39.

Souza MM, Andrade SG, Barbosa Jr AA, Santos TTM, Alves VAF, Andrade ZA 1996. Trypanosoma cruzi strains and autonomic nervous system pathology in experimental Chagas disease. Mem Inst Oswaldo Cruz 91: 217-224.

Tibayrenc M, Ayala F 1988. Isozyme variability in Trypanosoma cruzi, the agent of Chagas disease: genetical, taxonomical and epidemiological significance. Evolution 42: 277-292.

WHO 1986. Report of the steering committees research activities of the scientific working group (SWG) on Chagas disease. Mem Ins Oswaldo Cruz 81 (Suppl.): 181-244. 